\title{
Study on the Relationship of the Phenolic, Flavonoid and Tannin Content to the Antioxidant Activity of Garcinia Atroviridis
}

\author{
Ainnie Rahayu Abdullah ${ }^{1,2, *}$, Nor Aziyah Bakhari ${ }^{1}$, Hasnah Osman $^{3}$ \\ ${ }^{1}$ Department of Applied Sciences Universiti Teknologi MARA 13500 Permatang Pauh, Penang \\ ${ }^{2}$ Faculty of Applied Sciences, Universiti Teknologi MARA 40450 Shah Alam, Selangor \\ ${ }^{3}$ School of Chemical Sciences, Universiti Sains Malaysia 11800 Minden, Penang \\ *Corresponding Author: ainnie153@ppinang.uitm.edu.my
}

Copyright $(\underset{0}{2013}$ Horizon Research Publishing All rights reserved.

\begin{abstract}
The presence of phenolic, flavanoid and tannin compound content in the methanolic extract of Garcinia atroviridis were investigated in this study using UV-Vis Spectrometry and consequently find the relationship between the chemical contents with the antioxidant activity. Garcinia atroviridis has phenolic content the highest followed by flavonoid and tannin content. The antioxidant activities of dried sample of Garcinia atroviridis was carried out by using 2,2-diphenyl-1-picrylhydrazyl (DPPH) assay. The plant shows low antioxidant activity. Garcinia leaves from ethyl acetate extract showed the highest antioxidant activity (59.18\%) followed by Garcinia leaves from methanol extract (57.97\%), and then Garcinia leaves from hexane extract $(55.67 \%)$. The total phenolic content showed a good correlation with the antioxidant activity but not with the total flavonoid and tannin content.
\end{abstract}

Keywords Garcinia Atroviridis, Phenolic, Flavonoid, Tannin, 2,2-Diphenyl-1-Picrylhydrazyl (DPPH)

\section{Introduction}

Garcinia atroviridis also known as Asam Gelugor is common in the Malay Peninsula. Its fruit is cultivated throughout Southeast Asia for spice. The ripe fruits are bright orange yellow, which are sliced, dried and used in curries or stewed in plenty of sugar to be eaten [1]. Garcinia atroviridis also has been reported effectively in weight management on a short-term basis [2]. The fruit contains fruiting acids such as hydroxycitric acid or HCA that promotes fat burning and spares carbohydrate utilization at rest and during exercise [3]. The crude extracts of fruit and leaf of Garcinia atroviridis exhibited significant antifungal activity against Cladosporium herbrum. The root, leaf, trunk and stem bark extracts showed strong antioxidant activity [4].
Previous study on two new ester derivatives of garcinia acid, that is, 2-(butoxycarbonylmethyl)-3-butoxycarbonyl-2-hydr oxy-3-propanolide (1) and 1',1"'-dibutyl methyl hydroxycitrate (2), isolated from the fruits of Garcinia atroviridis, showed that only compound $\mathbf{1}$ exhibit antitumour-promoting activity although both compounds were neither toxic against the cells tested and brine shrimp nor were particularly antioxidant [5].

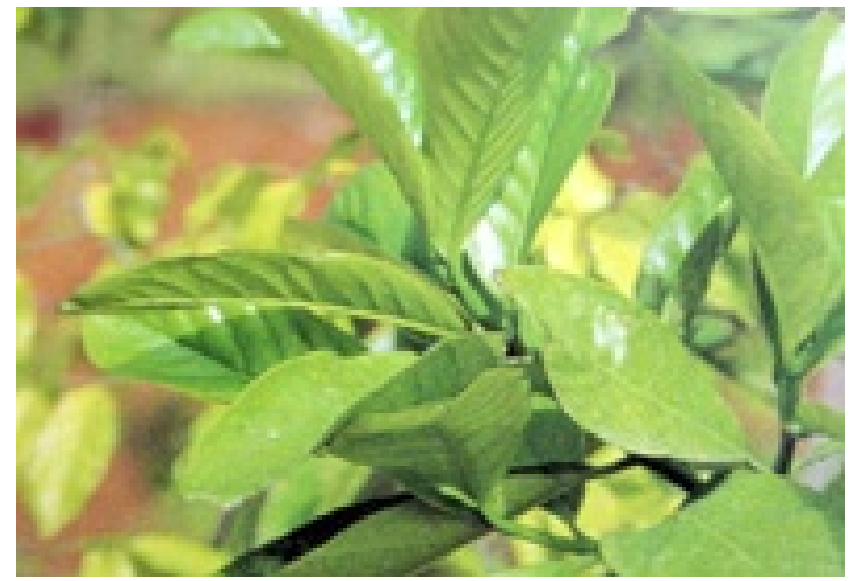

Figure 1. The leaves of Garcinia atroviridis

It is noted that a decoction of the leaves (Fig. 1) of the parent tree has been traditionally used for the treatment of ear ache [6]. In addition, the plant possesses anti-inflammatory properties and has been found useful in cases of acne. Although various studies have been conducted to investigate the pharmacological activities of Garcinia atroviridis, the chemical investigation to identify the compounds responsible for the precise biological mode of action of this natural product has not yet been reported [6]. This study, therefore, was carried out to measure the total content of phenolic, flavonoid and tannin compounds present in the methanolic extract of Garcinia atroviridis and to find the relationship between the chemical contents with the 
antioxidant activity of extract.

\section{Materials and Methods}

\subsection{Research Materials}

All the solvents and chemicals used were analytically graded. Garcinia atroviridis was collected from Tasik Gelugor, Penang, Malaysia. The leaves and stems of this plant were used in the investigation.

\subsection{Extraction of Samples}

The fresh leaves of Garcinia atroviridis were cleaned and washed under running tap water. The excessive water was dripped off and the leaves were then dried in the oven at 40 ${ }^{0} \mathrm{C}$ for a few days and then ground into powders. The dried powdered sample was defatted using petroleum ether before exhaustively extracted with methanol using soxhlet apparatus. The resulting methanol extract were filtered through Whatman No. 1 filter paper and the filtrates were evaporated under reduced pressure at $40{ }^{\circ} \mathrm{C}$ using a rotary-evaporator (Rotavapor, Buchi) to give crude methanol $(\mathrm{MeOH})$ extract. The crude extract was then fractionated into hexane $(\mathrm{H})$ extract and ethyl acetate (EA) extract using solvent extraction procedures.

\subsection{Measurement of Total Phenolic Content (TPC)}

Total phenolic content in the plant was estimated by using Folin Ciocalteu assay [7]. Briefly, $0.25 \mathrm{~mL}$ (100 ppm) sample, $3.75 \mathrm{~mL}$ of Folin Ciocalteu reagent (1:15 ; Folin Ciocalteu reagent:distilled water) were put in a vial. After 3 minutes, $1.25 \mathrm{~mL}$ of $\mathrm{Na}_{2} \mathrm{CO}_{3}$ is added and shake thoroughly before allowing them in water bath $\left(40{ }^{\circ} \mathrm{C}\right)$ for 30 minutes. Then, all the samples of $100 \mathrm{ppm}$ were measured their TPC by using UV- Vis $(685 \mathrm{~nm})$. Each sample was measured in triplicate. The results were expressed as mg Quercetin equivalents / weight of dried plant material and mg Catechin equivalents / weight of dried plant material.

\subsection{Measurement of Total Flavonoid Content (TFC)}

A volume of $5 \mathrm{~mL}$ of the sample and $5 \mathrm{~mL}$ of $\mathrm{AlCl}_{3} 2 \%$ were placed in vials and allowed to stand for 5 minutes at room temperature. Then, all the samples of $100 \mathrm{ppm}$ were measured their TFC by using UV-Vis (415 nm). Each sample was measured in triplicate. Results were expressed as $\mathrm{mg}$ Quercetin equivalents / weight of dried plant material and $\mathrm{mg}$ Catechin equivalents / weight of dried plant material [8].

\subsection{Measurement of Total Tannin Content (TTC)}

A volume of $3.0 \mathrm{~mL}$ sample, $3.0 \mathrm{~mL}$ of vanillin $4 \%$ in methanol, $1.5 \mathrm{~mL} \mathrm{HCl} 37 \%$ were put in vials and were incubated in dark for 10 minutes. Then, all the samples of $100 \mathrm{ppm}$ were measured their TTC by using UV-Vis (500 $\mathrm{nm}$ ). Each sample was measured in triplicate. Results were expressed as mg Quercetin equivalents / weight of dried plant material and $\mathrm{mg}$ Catechin equivalents / weight of dried plant material [9].

\subsection{Free radical-Scavenging Activity}

Effect of the extract on DPPH free radical was measured based on DPPH (1,1-diphenyl-2-picrylhydrazyl) assay [10]. A volume of $4 \mathrm{~mL}$ sample extract of various concentration and $0.5 \mathrm{~mL}$ DPPH were placed in vials and incubated in dark for 30 minutes at room temperature before measuring the absorbance (A). Vitamin E, quercetin, catechin and BHT are the standard references. Readings for the extract and standards were carried out in triplicate.

\section{Results and Discussion}

\subsection{Total Phenolic, Flavanoid and Tannin Content}

The total phenolic, flavonoid and tannin content and antioxidant activity varies among sample extracts. Total phenolic, flavonoid and tannin content are shown in Table 1.

Table 1. Total Phenolic Content (TPC), Total Flavanoid Content (TFC) and Total Tannin Content (TTC)

\begin{tabular}{|c|c|c|c|c|c|c|}
\hline SAMPLE & \multicolumn{2}{|c|}{ TPC $(\mathrm{mg} / \mathrm{g})$} & \multicolumn{2}{c|}{ TFC $(\mathrm{mg} / \mathrm{g})$} & $\mathrm{TTC}(\mathrm{mg} / \mathrm{g})$ & \\
\hline & $\mathrm{Q}^{\mathrm{a}}$ & $\mathrm{C}^{\mathrm{b}}$ & $\mathrm{Q}^{\mathrm{a}}$ & $\mathrm{C}^{\mathrm{b}}$ & $\mathrm{Q}^{\mathrm{a}}$ & $\mathrm{C}^{\mathrm{b}}$ \\
\hline G.L. $(\mathrm{H})$ & 103.33 & 92.38 & 47.28 & 47.21 & 25.00 & 13.19 \\
\hline G.L.(EA) & 113.16 & 100.86 & 23.48 & 23.41 & 5.91 & 0.06 \\
\hline G.L.(MeOH) & 102.63 & 91.77 & 1.66 & 1.59 & 6.36 & 0.38 \\
\hline G.S.(H) & 9.12 & 11.02 & 0.28 & 0.21 & 9.09 & 2.25 \\
\hline G.S.(EA) & 20.00 & 20.41 & 0.34 & 0.28 & 7.73 & 1.31 \\
\hline G.S.(MeOH) & 15.26 & 16.32 & 0.90 & 0.83 & 7.73 & 1.31 \\
\hline
\end{tabular}

a Expressed in milligrams of Quercetin per gram weight of dried plant material;

bExpressed in milligrams of Catechin per gram weight of dried plant material;

G.L.- Garcinia leaves; G.S.- Garcinia stems 
Table 2. Absorbance of $100 \mathrm{ppm}$ concentration for DPPH Scavenging Activity

\begin{tabular}{|c|c|c|c|c|c|c|c|c|}
\hline \multirow{2}{*}{ SAMPLE } & \multicolumn{7}{|c|}{ Concentration (ppm) } \\
\cline { 2 - 9 } & 0 & 5 & 10 & 20 & 30 & 40 & 50 & 100 \\
\hline VITAMIN E & 0.956 & 0.554 & 0.525 & 0.514 & 0.471 & 0.429 & 0.323 & 0.192 \\
\hline BHT & 0.954 & 0.626 & 0.617 & 0.551 & 0.479 & 0.432 & 0.423 & 0.367 \\
\hline QUERCETIN & 0.935 & 0.513 & 0.509 & 0.421 & 0.406 & 0.045 & 0.039 & 0.030 \\
\hline CATECHIN & 0.947 & 0.522 & 0.513 & 0.478 & 0.433 & 0.114 & 0.132 & 0.144 \\
\hline G.L (H) & 0.952 & 0.798 & 0.784 & 0.786 & 0.784 & 0.657 & 0.486 & 0.434 \\
\hline G.L (EA) & 0.955 & 0.708 & 0.697 & 0.679 & 0.491 & 0.457 & 0.413 & 0.321 \\
\hline G.L (MeOH) & 0.954 & 0.654 & 0.656 & 0.646 & 0.445 & 0.449 & 0.473 & 0.366 \\
\hline G.S (H) & 0.906 & 0.814 & 0.801 & 0.799 & 0.754 & 0.617 & 0.514 & 0.442 \\
\hline G.S (EA) & 0.948 & 0.778 & 0.687 & 0.668 & 0.643 & 0.512 & 0.443 & 0.416 \\
\hline G.S (MeOH) & 0.957 & 0.783 & 0.759 & 0.772 & 0.761 & 0.545 & 0.483 & 0.447 \\
\hline
\end{tabular}

\subsection{Antioxidant Activity}

The antioxidant activity of all sample extracts was estimated by DPPH assay. The DPPH assay is a very convenient method for screening small antioxidant molecules because the reaction can be analysed by simple spectrophotometric assays [11].

The antioxidant activity indicated the ability of the sample extracts to neutralize free radical compound. The absorbance of all sample extract are shown in Table 2.

The high absorbance values indicated the ability of the sample to reduce radical activity. The original Blois [12] method summarized the reaction of DPPH radical activity as below

$$
\begin{array}{r}
\mathrm{Z}^{*}+\mathrm{RSH}=\mathrm{ZH}+\mathrm{RS}^{\bullet} \\
\mathrm{RS}^{\bullet}+\mathrm{RS}^{\bullet}=\mathrm{RS}-\mathrm{RS}
\end{array}
$$

The deep violet colour of DPPH was reduced to pale yellow colour which shows that the free radical is accepting hydrogen atom from hydrogen donor.

Table 3 shows the trend of inhibition percentage of all sample extracts including reference standards (quercetin, catechin, vitamin $\mathrm{E}$ and $\mathrm{BHT}$ ). The sequence of the inhibition percentage of all sample extracts including reference standards for $100 \mathrm{ppm}$ is as follows: Quercetin $>$ Catechin $>$ Vit E $>$ BHT $>$ G.L $($ EA) $>$ G.L $(\mathrm{MeOH})>$ G.L $(\mathrm{H})>$ G.S $(\mathrm{EA})>$ G.S $(\mathrm{MeOH})>\mathrm{G} . \mathrm{S}(\mathrm{H})$.

Basically, the trends follow the polarity of solvent. Quercetin is an example of flavonoid compound. Flavonoid had been reported to exhibit great potential antioxidant activity [13]. The phenomenon in this study is acceptable since quercetin has highest inhibition percentage inhibits free radical activity.

Ismail and Shaari [14] reported that the leaves of the plant have higher inhibition percentage than the stems. From this study, it is found that ethyl acetate extract of Garcinia leaves has high potential to scavenge free radical molecule as its inhibition percentage is the highest than all Garcinia sample leaves extract whereas Garcinia stem has the lowest inhibition percentages in scavenge free radical activity. This indicates that the ethyl acetate extract of the leaves have better potential as antioxidant agent among others. If the inhibition percentage is more than $90 \%$, the sample is said to have a great potential antioxidant activity. With only $60 \%$ $90 \%$ of the inhibition percentage, the sample is said to have moderate potential antioxidant activity whereas the value below $60 \%$, the sample has low potential antioxidant activity [15].

However, from this study, ethyl acetate, methanol and hexane extracts of Garcinia leaves have slightly low potential antioxidant activity as the inhibition percentage range just below $60 \%$. This could be due to the stability of the polyphenol compound. Phenolic, flavonoid and tannin however, are unstable compounds [16-18].

The temperature during drying process might cause the degradation of some of the polyphenol substituents [19]. Climatic growth conditions, duration of storage and the cultivation of the plant may influence the antioxidant activity [20].

Garcinia is a rich source of xanthones, flavonoid, benzophenone, lactones and phenolic acid [21]. Xanthones are known of their biological activity such as antibacterial, antidiabetic, antiplasmodial, human cancer cell line growth inhibition, antihypertensive and vasorelaxing, cardiovascular protection, inhibition of HIV-1 reverse transcriptase and HIV-1 replication. Benzophenones have been shown to possess cytoprotection against HIV-1 in vitro, antimicrobial properties, antioxidant activity, and cytotoxic activity [22]. 
Table 3. DPPH Scavenging Activity (\% Inhibition)

\begin{tabular}{|c|c|c|c|c|c|c|c|c|}
\hline \multirow{2}{*}{ SAMPLE } & \multicolumn{7}{|c|}{ Concentration (ppm) } \\
\cline { 2 - 9 } & 0 & 5 & 10 & 20 & 30 & 40 & 50 & 100 \\
\hline VITAMIN E & 0 & 42.05 & 45.08 & 46.23 & 50.73 & 55.13 & 66.21 & 79.92 \\
\hline BHT & 0 & 34.38 & 35.32 & 42.24 & 49.79 & 54.72 & 55.66 & 61.53 \\
\hline QUERCETIN & 0 & 45.13 & 45.56 & 54.97 & 56.58 & 95.19 & 95.83 & 96.79 \\
\hline CATECHIN & 0 & 44.88 & 45.83 & 49.52 & 54.28 & 87.96 & 86.06 & 84.79 \\
\hline G.L (H) & 0 & 16.18 & 17.65 & 17.44 & 17.65 & 30.99 & 54.73 & 55.67 \\
\hline G.L (EA) & 0 & 25.86 & 27.02 & 28.90 & 48.95 & 52.53 & 59.07 & 59.18 \\
\hline G.L (MeOH) & 0 & 31.45 & 31.24 & 32.29 & 52.31 & 52.94 & 54.51 & 57.97 \\
\hline G.S (H) & 0 & 10.15 & 11.59 & 11.81 & 16.78 & 31.90 & 44.04 & 51.88 \\
\hline G.S (EA) & 0 & 17.93 & 27.56 & 29.54 & 32.17 & 45.99 & 54.22 & 54.96 \\
\hline G.S (MeOH) & 0 & 18.18 & 20.69 & 19.33 & 20.48 & 43.05 & 43.05 & 54.75 \\
\hline
\end{tabular}

According to Khokhar and Apenten [23], it is possible that the antioxidant activity is influenced by the presence of hydroxyl group. The antioxidant activity is also very dependent on the number and position of the hydroxyl group presence in the molecules [13]. $\mathrm{IC}_{50}$ is a measure of the effectiveness of a compound in inhibiting biological or biochemical function or in other words, it is the half maximal $(50 \%)$ inhibitory concentration (IC) of a substance $(50 \%$ IC, or $\left.\mathrm{IC}_{50}\right) \cdot \mathrm{IC}_{50}$ of sample extracts and standard is shown in Table 4. The sequence of the sample extracts and the reference standard is as follows: G.S $(\mathrm{H})>$ G.S $(\mathrm{MeOH})>$ G.L $(\mathrm{H})>$ G.S (EA) G.L (EA) > BHT > Vit E, G.L $(\mathrm{MeOH})>$ Catechin $>$ Quercetin. A lower value of $\mathrm{IC}_{50}$ indicates a higher antioxidant activity [14].

Table 4. $\mathrm{IC}_{50}$ in concentration (ppm)

\begin{tabular}{|c|c|}
\hline SAMPLE & Conc. (ppm) \\
\hline VITAMIN E & 28.40 \\
\hline BHT & 30.72 \\
\hline QUERCETIN & 15.00 \\
\hline CATECHIN & 21.80 \\
\hline G.L (H) & 49.72 \\
\hline G.L (EA) & 32.88 \\
\hline G.L (MeOH) & 28.40 \\
\hline G.S (H) & 87.59 \\
\hline G.S (EA) & 45.00 \\
\hline G.S (MeOH) & 80.43 \\
\hline
\end{tabular}

Comparison of total phenolic content, total flavonoid content and total tannin content with the antioxidant activity is shown in Figs. 2, 3 and 4 respectively. Several studies have reported on the relationships between phenolic content and the antioxidant activity. Some authors found a correlation between the phenolic content and the antioxidant activity, while others found no such relationship. According to Velioglu [24] and coworkers, there is a strong relationship between total phenolic content and antioxidant activity in selected fruits, vegetables and grain products. However, studies conducted by Kähkönen [25] and coworkers on some plant extracts containing phenolic compounds found that there is no correlation between phenolic content and antioxidant activity. Fig. 2 shows that the antioxidant activity has correlation with the total phenolic content. This finding was in agreement with Velioglu [24]. Ethyl acetate extract was found to have the highest antioxidant activity and also highest content of phenolic compounds.

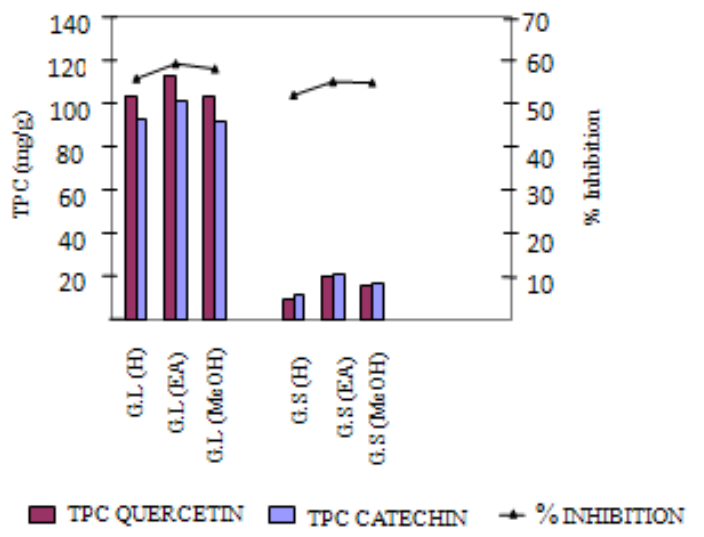

Figure 2. Graph comparison between inhibition percentage and the total phenolic content (TPC) of all sample extracts.

Figs. 2 and 3 showed that there are no relationships between the antioxidant activity with the total flavonoid 
content and total tannin content. For example, the hexane extracts of Garcinia leaves show the highest content of flavonoid and tannin compounds, but its antioxidant activity is low.

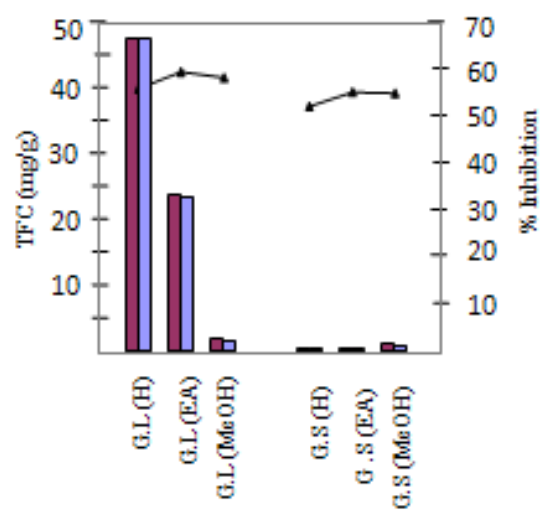

TFC QUERCETIN $\square$ TFC CATECHIN + \%IMHIITION

Figure 3. Graph comparison between inhibition percentage and total flavonoid content (TFC) of all sample extracts.

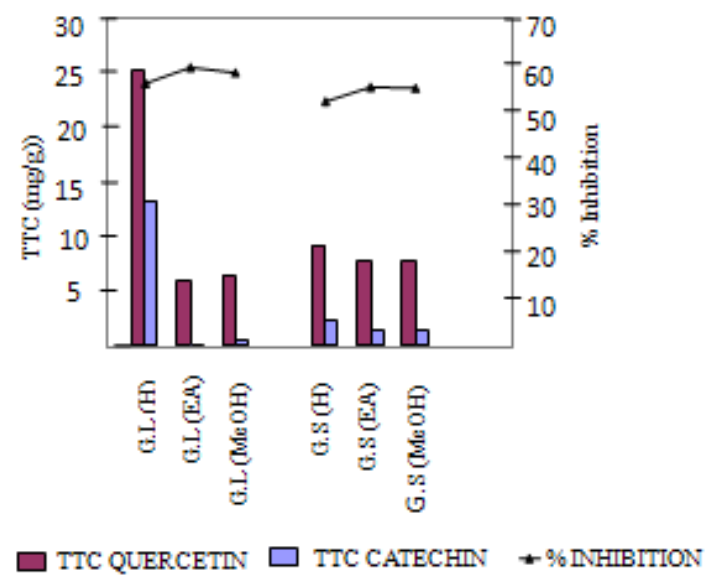

Figure 4. Graph comparison between inhibition percentage and total tannin content (TTC) of all sample extracts

\section{Conclusion and Recommendation}

Ethyl acetate extract of Garcinia atroviridis has the highest total phenolic, flavonoid, tannin content compared to methanol and hexane extract. However, the sample extracts of dried plant of Garcinia atroviridis have low potential as antioxidant agent. The inhibition percentages were $59.18 \%$ (ethyl acetate extract), 57.97\% (methanol extract) and 55.67\% (hexane extract) respectively.

This study shows that the leaves of Garcinia have higher antioxidant activity than their stems. The result also shows that there is a correlation between total phenolic content to the inhibition activity percentage. No close correlations were observed between total flavonoid content and total tannin content to the inhibition activity percentage.

For further research, it is recommended to isolate the pure phenolic, flavanoid and tannin compounds present in the ethyl acetate extract of the dried leaves of Garcinia atroviridis using various isolation techniques and identify its structure using various spectroscopic techniques. It is also important to identify other types of compounds that are present because detailed information on the chemical compounds present in the extract would enable us to decide whether the plant is safe to be taken orally or not.

\section{Acknowledgements}

Special thank to the Department of Applied Sciences, UiTM Penang and School of Chemistry, USM, Penang for providing necessary laboratory facilities needed to perform this study.

\section{REFERENCES}

[1] D.W.E. Hassan. Healing Herbs of Malaysia, Kuala Lumpur: Federal Land Development Agency, 2006.

[2] http://www.naturalproductinsider.com/ : accessed on 4 February 2009.

[3] A.C. Sullivan, J. Triscari, J.G. Hamilton, O.N. Miller and V.R. Wheatley, Lipids, 9, 121-128, 1974.

[4] N.M. Mackeen, A.M. Ali, N.H. Lajis, K. Kawazu, Z. Hassan, M. Amran, M. Habsah, L.Y. Mooi and S.M. Mohamed. Antimicrobial, antioxidant, antitumour-promoting and cytotoxic activities of different plant part extracts of Garcinia atroviridis griff. ex T. anders, J. Ethnopharmacol. 72, 395-402, 2000.

[5] N.M. Mackeen, L.Y. Mooi, M. Amran, N. Mat, N.H. Lajis and A.M. Ali. Noncytotoxic and antitumor-promoting activities of garcinia acid esters from Garcinia atroviridis griff. ex T. anders, (Guttiferae), Evid, Based Compliment Alternat Med.. Published online 2012 May 28, 2012.

[6] E.J. Tisdale, D.A. Kochman and E.A. Theodorakis. Total synthesis of atroviridin. Pergamon, Tetrahedron Letters (44), 3281-3284, 2003.

[7] V.S. Neergheen, M.A. Soobrattee,T. Bahorun and O.I. Aruoma. Characterization of the phenolic constituents in Mauritian endemic plants as determinants of their antioxidant activities in vitro, Journal of Plant Physiology, 163, 787-799, 2006.

[8] A. Meda, C.E. Lamien, M. Romito, J. Millogo and O.G. Nacoulma. Determination of the total phenolic, flavonoid and proline contents in Burkina Fasan honey, as well as their radical scavenging activity, Food Chemistry, 91, 571-577, 2005.

[9] K.W.C. Sze-Tao, J.E. Schrimpf, S.S. Teuber, K.H. Roux and S.K. Sathe. Effects of processing and storage on walnut (Juglans regia L.) tannins, Journal of Science and Food Agriculture, 81(13), 1215-1222, 2001.

[10] Abdul Rahim, E. Rocca, J. Steinmetz, M.J. Kassim, M.S. 
Ibrahim and H. Osman. Antioxidant activities of mangrove Rhizophora apiculata bark extracts, Food Chemistry, 107 200-207, 2008.

[11] Sanchez-Moreno, J.A. Larrauri and Sauro-Calixto. F.A. Procedure to measure the antiradical efficiency of polyphenols, J. Sci. Food Agric., 76, 270-276, 1998.

[12] M.S. Blois. Antioxidant determinations by the use of a stable free radical, Nature, 181, 1199-1200, 1958.

[13] O. Farkas J. Jakus and K. Hérberger. Antioxidant activity relationships of flavonoids compounds, International Journal of Molecular Sciences, 9, 1079-1088, 2004.

[14] N.H. Ismail and K. Shaari. Beyond Medicinal Plants, Reality and challenges in antidiebetic research, University Publication Centre (UPENA) UiTM, 109-113, 2008.

[15] K. Kruawan and K. Kangsadalampai. Antioxidant activity, phenolic compound contents and antimutagenic activity of some water extract of herbs, Thai J.Pharm.Sci, 30, 28-35, 2006.

[16] A. Ismail, Z.M. Marjan and C.W. Fong. Total antioxidant activity and phenolic content in selected vegetables, Food Chemistry, 87, 581-586, 2004.

[17] R. Zadernowski, M. Naczk and J. Nesterowicz. Phenolic acid profiles in somesmall berries, Journal of Agricultural and Food Chemistry, 53(6), 2118-21, 2005.

[18] M.M. Giusti, and R.E. Wrolstad. Anthocyanins: Characterization and measurement of anthocyanins by UV-Visible spectroscopy. In R. E. Wrolstad (Ed.), Current protocols in food analytical chemistry. New York: John Wiley \& Sons, Unit F1. 2, 1-13, 2001.
[19] R.C. Dutra, M.N. Leite and N.R. Barbosa. Quantification of phenolic of Pterodon emarginatus vogel seeds, International Journal of Molecular Sciences, 9, 606-614, 2008.

[20] G. Gazzani, A. Papetti, G. Massolini and M. Daglia. Anti- and prooxidant activity of water soluble components of some common diet vegetables and the effect of thermal treatment, Journal of Agricultural and Food Chemistry, 46, 4118-4122, 1998.

[21] G.S. Joseph, G.K. Jayaprakasha, A.T. Selvi, B.S. Jena and K.K.Sakariah. Antiflatoxigenic and antioxidant activities of Garcinia extracts, International Journal of Food Microbiology, 101, 153-160, 2005.

[22] B.N. Lenta, C. Vonthron-Sénécheau, B. Weniger, K.P. Devkota, J. Ngoupayo, M. Kaiser, Q. Naz, M.I. Choudhary, E. Tsamo and N. Sewald. Leishmanicidal and cholinesterase inhibiting activities of phenolic compounds from Allanblackia monticola and Symphonia globulifera, International Journal of Molecular Sciences, 12, 1548-1557, 2007.

[23] S. Khokhar and R.K.O. Apenten. Iron binding characteristics of phenolic compounds: some tentative structure-activity relations, Food Chem., 81, 133-140, 2003.

[24] Y.S. Velioglu, G. Mazza, L. Gao,and B.D. Oomah. Antioxidant activity and total phenolics in selected fruits, vegetables, and grain products, Journal of Agricultural and Food Chemistry , 46, 4113-411, 1998.

[25] M.P. Kähkönen, A.I. Hopia, H.J. Vuorela, J.P. Rauha, K. Pihlaja, T.S. Kujala and M. Heinonen. Antioxidant activity of plant extracts containing phenolic compounds, Journal Agricultural and Food Chemistry, 47, 3954-3962, 1999. 